\title{
ANÁLISE DE VIABILIDADE ECONÔMICA DE IMPLEMENTAÇÃO DA CULTURA DO MARACUJÁ EM UMA PROPRIEDADE NO SERTÃO DE PERNAMBUCO
}

Júlio Cesar Vasconcelos Conserva (UFCG/CDSA) julio.conserva@ outlook.com Lucas da Silva Almeida (UFCG/CDSA) lucameid@gmail.com Yan Rink Aguiar Feitoza (UFCG/CDSA) yanrink08@gmail.com João Pedro Marques Sousa (UFCG/CDSA) pedro321joao@ hotmail.com Marcelo da Silva Ribeiro Rodrigues (UFCG/CDSA) marcelo.srrod@gmail.com

\section{Resumo}

Tendo em vista as oportunidades geradas pelo forte ramo da fruticultura no Brasil e levando em consideração a dificuldade de pequenos produtores no domínio de ferramentas de análise econômica de projetos, o presente artigo tem como objetivo avaliar a implementação da cultura do maracujá em um hectare de terra na propriedade do senhor Francisco Nicolau de Sousa Santos, no Sítio Timbaúba, localizado em São José do Egito-PE, bem como demonstrar sua viabilidade econômica, visando a obtenção de uma renda considerável ao produtor. Foi fornecido ao solicitante as etapas para implementação da cultura e a análise de viabilidade financeira da mesma, através de indicadores como o Payback, VPL, TIR e Relação Custo/Benefício. O produtor, já com posse de muitos materiais necessários a implementação, terá seu custo inicial reduzido, o que influi também na sua receita final. Os resultados apontam que o projeto possui um Payback de retorno em 2,4 meses, bem como VPL de 67.312,15, TIR de $252 \%$ e Relação Custo/Benefício de 2,5790, o que mostra a viabilidade econômica do empreendimento.

Palavras-Chaves: (Engenharia Econômica; Viabilidade Econômica; Maracujá; Projeto.)

\section{Introdução}

De acordo com o Serviço Brasileiro de Apoio às Micro e Pequenas Empresas (Sebrae, 2016), o ramo da fruticultura é um dos setores que possui maior destaque no agronegócio brasileiro, tornando o Brasil o terceiro maior produtor no ranking mundial.

Segundo a Empresa Brasileira de Pesquisa Agropecuária (Embrapa, 2016), o Nordeste é líder na produção do maracujá amarelo e destaca-se com uma participação de 64,9\% em âmbito nacional. Em 2019 o mercado se apresenta amplamente favorável e com grande otimismo para 
o próximo ano, graças a desburocratização e chegada de investimentos. Dados da Embrapa ainda mostram que a produção brasileira em 2010 foi de 920 mil toneladas, cerca de $70 \%$ da

produção mundial. A produtividade média brasileira é estimada em 14 toneladas de hectare por ano. Mas o potencial da cultura pode chegar a 50 toneladas de hectare por ano, com o uso de espécies melhoradas geneticamente.

Com o cenário econômico de perspectiva favorável o estado do Pernambuco ocupa a $12^{\circ}$ colocação na produção do maracujá levando em conta toda produção brasileira (Embrapa,2017). Diante dessa situação um novo produtor da cidade de São José do Egito situada no sertão nordestino onde o maracujá amarelo está sendo uma das opções para cultivo dos pequenos produtores locais, tentando aproveitar a vantagem competitiva da região e assim investir no cultivo do fruto, necessita de uma análise de viabilidade econômica para saber-se a rentabilidade do empreendimento.

Diante disso, a análise de viabilidade econômica é um estudo essencial para empresas que estão entrando em novos mercados, pois o mesmo dá a oportunidade de o gestor tomar decisões de investir ou não em uma produção, de acordo com a sua rentabilidade. No entanto, pequenos produtores possuem dificuldade na utilização dessas ferramentas, de modo que desconhecem a rentabilidade de suas produções. Diante disso, torna-se importante verificar a viabilidade econômica do cultivo de maracujá amarelo desse pequeno produtor. Assim, o gestor poderá analisar de maneira precisa se o negócio trará prejuízo ou não, levando em consideração uma previsão com relação ao ciclo produtivo da planta.

\section{Fundamentação teórica}

\subsection{Mercado do Maracujá}

É uma cultura com longo período de safra de oito meses no sudeste, de dez no nordeste e de doze meses no norte do país, permitindo, por isso, um fluxo equilibrado de renda mensal (LIMA et al.,1994). O autor ainda diz que esse fator contribui para elevar o padrão de vida de pequenos produtores rurais, com plantações conduzidas em base familiar.

Para Dantas (2014), “O cultivo do maracujazeiro desperta o interesse tanto no setor rural quanto nas indústrias, visto que ele possui uma vasta gama de produtos e subprodutos, servindo de base para a produção de alimentos, remédios, cosméticos e sucos". E ressalta ainda que a produção 
de maracujá é fundamental importância para o desenvolvimento econômico e social do país, servindo de fonte de renda para pequenos e médios produtores, contribuindo para a fixação do homem a terra.

O rendimento médio da cultura pode-se estimar em um plantio bem conduzido, um rendimento por hectare de 8 a 10 toneladas no primeiro ano, de 15 a 20 toneladas no segundo e de 12 a 14 toneladas no terceiro ano (FREIRE FILHO et al.,2016).

De acordo com informações da revista ABRAFRUTAS (2019), o Brasil é atualmente o maior produtor mundial de maracujá, produzindo por ano um milhão de toneladas da fruta. A produtividade alcançada, no entanto, é considerada baixa - a média é de 14 toneladas/ha/ano. Quando o produtor adota cultivares melhoradas geneticamente e tecnologias adequadas ao sistema de produção, a produtividade pode ultrapassar 50 toneladas/ha/ano

Tendo como base os dados de Lima et al. (1994), que mostram que o maracujá se adapta muito bem as condições do Nordeste, e com isso, aumentando o interesse por essa fruta que é pouca explorada pelos agricultores do sertão de Pernambuco, criando assim condições de mercado favoráveis a quem adota esse tipo de cultura.

Notou-se que o mercado oferece oportunidades para a oferta desse fruto, já que os consumidores estão em busca de frutas com qualidade e preços baixos, parâmetros que hoje não são perceptíveis e nem oferecidos pelo mercado interno como aborda Mondaini e Kinpara (2003).

De acordo com pesquisas qualitativas feitas, tais parâmetros não são atendidos em virtude das grandes distancias dos centros de distribuições, afetando diretamente a qualidade, e implicando em custos logísticos que elevam os preços da fruta.

Diante das informações de Dantas (2014) é notório uma facilidade para o escoamento desse produto, e para atestarmos as mesmas se fez necessário a análise de viabilidade e assim comprovar que se trata de um investimento atrativo, tornando o produtor pioneiro dessa cultura na região.

\subsection{Avaliação da viabilidade econômica}

O estudo de viabilidade econômica abrange etapas referentes às análises sobre o mercado que pretende atuar, seguida pela projeção de faturamento para o cálculo dos indicadores que avaliarão a viabilidade do empreendimento (ROZENFELD et al., 2006). 
Dentre os principais indicadores de investimentos utilizados para a avaliação da viabilidade econômica de um projeto, estão às avaliações dos investimentos a partir do Valor Presente Líquido (VPL), da Taxa Interna de Retorno (TIR), Relação Benefício/Custo (B/C), e o Payback Simples (PBS).

Segundo Matos (2002), as decisões sobre a viabilidade econômica de projetos de investimento resultam da estimativa e análise de indicadores de viabilidade. Estes indicadores atuam como ferramentas preditivas para saber se o investimento terá retornos positivos ou se será economicamente inviável.

\subsubsection{Payback}

Uma definição precisa para payback é dada por Rezende e Oliveira (2001), o período é calculado com o intuito de verificar o espaço de tempo necessário para que os recursos investidos sejam recuperados.

A relação do payback é lógica e simples, habitualmente, quando menor um investimento, em menos tempo o valor investido irá retornar ao investidor, de forma análoga, quanto maior o valor investido, mais tempo irá demorar até que o valor investido retorne ao investidor além de que, Segundo Souza e Clemente (2008) o payback é interpretado como um indicador de risco.

O payback simples pode ser mensurado a partir de uma equação simples conforme Mondaini e Kinpara (2003), de modo a relacionar a razão entre o saldo acumulado multiplicado pelo intervalo de tempo e o saldo em caixa do ano seguinte.

$$
P B=\frac{S_{n} \cdot t}{S C_{n+1}}
$$

Onde:

$S_{n} \rightarrow$ Saldo acumulado no período $\mathrm{n}$.

$S C_{n+1} \rightarrow$ Saldo em caixa do período $\mathrm{n}+1$.

$P B \rightarrow$ Intervalo temporal que se dará o Payback.

$t \rightarrow$ Intervalo temporal escolhido. 


\subsubsection{Valor Presente Líquido (VPL)}

Rezende e Oliveira (2001), o VPL é um dos indicadores mais utilizados na análise de viabilidade econômica de um projeto.

De modo geral, o VPL serve como indicador de viabilidade econômica de um investimento, caracterizando como uma ferramenta de alta precisão e dinâmica, que fornece dados que podem ser analisados do ponto de vista econômico de modo simples. De maneira mais técnica, o valor mensurado através do cálculo do VPL representa o valor que aquele investimento pode gerar.

Para se determinar o VPL, utiliza-se a fórmula oferecida pela matemática financeira (MONDAINI \& KINPARA, 2003):

$$
V P L=\frac{F L_{0}}{(1+k)^{0}}+\frac{F L_{1}}{(1+k)^{1}}+\cdots+\frac{F L_{n}}{(1+k)^{n}}
$$

Onde:

$V P L \rightarrow$ Valor Presente Líquido.

$F L_{n} \rightarrow$ Fluxo líquido do ano $\mathrm{n}$.

$k \rightarrow$ Taxa de desconto.

$n \rightarrow$ Ano do horizonte do projeto.

\subsubsection{Taxa Interna de Retorno}

De acordo com Hoji (2006), a Taxa Interna de Retorno (TIR) é conhecida também como taxa de desconto do fluxo de caixa.

A TIR pode ser definida como a taxa de retorno de um terminado projeto, que se comporta de acordo com o fluxo de caixa, de modo, segundo Neto (2006) normalmente, o fluxo de caixa no momento zero (fluxo de caixa inicial) é representado pelo valor do investimento, ou empréstimo ou financiamento; os demais fluxos de caixa indicam os valores das receitas ou prestações devidas. 
Hoji (2006) ainda diz que o conceito de TIR é comumente utilizado para determinar taxas quando existe mais de um pagamento e mais de um recebimento ou quando as parcelas de pagamento ou recebimento não são uniformes.

A taxa interna de retorno pode ser mensurada através da seguinte fórmula, que trata para isso, o VPL como sendo nulo.

A taxa interna de retorno pode ser calculada, segundo Mondaini e Kinpara (2003), como:

$$
V P L=0=\sum_{t=0}^{T} \frac{F L_{t}}{(1+k)^{t}}
$$

Onde:

$F L_{1}, F L_{2}, \ldots, F L_{n} \rightarrow$ Fluxos de caixa para $n$ períodos.

$t \rightarrow$ Período estudado.

$k \rightarrow$ Taxa de desconto.

$T \rightarrow$ Período total.

$V P L \rightarrow$ Valor Presente Líquido.

\subsubsection{Relação Benefício/Custo}

O RBC funciona como um indicador de viabilidade econômica que permite analisar uma representação do retorno por unidade de capital ao longo de um período. Segundo Nogueira (2001), para um projeto ser viável economicamente, esta relação, em princípio, deverá ser maior que 1 , ou seja, $\mathrm{RBC}>1$.

Esta relação pode ser obtida através da seguinte equação citada por Mondaini e Kinpara (2003):

$$
B / C=\frac{\frac{B_{0}}{(1+k)^{0}}+\frac{B_{1}}{(1+k)^{1}}+\cdots+\frac{B_{n}}{(1+k)^{n}}}{\frac{C_{0}}{(1+k)}+\frac{C_{1}}{(1+k)^{1}}+\cdots+\frac{C_{n}}{(1+k)^{n}}}
$$

Onde:

$B_{n} \rightarrow$ Entradas do fluxo de caixa.

$c_{n} \rightarrow$ Saídas do Fluxo de caixa.

$k \rightarrow$ Taxa de desconto.

$n \rightarrow$ Horizonte do projeto em anos. 


\section{Metodologia}

Os procedimentos utilizados para este artigo incluíram os seguintes pontos:

a) Pesquisa bibliográfica, que consistiu em analisar, pesquisar e observar o ramo da produção de Maracujá, tomando como base, as ferramentas de análise de viabilidade econômica.

b) Pesquisa de informe sobre o setor, utilizando dos seguintes métodos:

- Estatísticas do mercado do Maracujá;

- Sites de notícias que apresentassem informações relevantes sobre o ramo;

- Entrevistas informais com o investidor, e comerciantes locais a fim de coletar informações sobre o negócio;

- Livros e artigos publicados em revistas ou eventos científicos;

c) Aplicação das ferramentas de Payback, VPL, TIR e B/C para avaliar a viabilidade financeira do projeto.

\subsection{Implantação do projeto no sitio Timbaúba}

O Projeto será implementado na fazenda Timbaúba, localizada na cidade de São José do EgitoPE, de proprietário Francisco Nicolau de Sousa Santos.

O Proprietário da terra dispõe de mais de um hectare de área para cultivo das mudas de maracujá, localizada na margem de um rio. O solo é arenoso, propício ao plantio da muda, onde existem dificuldades para encharco e onde outrora já foram introduzidas outras culturas de frutas, onde um poço artesiano fazia a irrigação com sistema de gotejamento.

No Sistema de condução do maracujazeiro serão utilizados estacas e mourões que o proprietário já dispõe, advindos da retirada da algaroba, planta que não é típica do sertão; também já está sob a posse do agricultor a bomba submersa para irrigação advinda do rio que faz fronteira com a área a ser utilizada, bem como as mangueiras de gotejamento, caixa d'água e poço artesiano.

Na preparação e plantio das mudas, para aragem do solo, será usada tração animal, devido o local escolhido ser desfavorável ao uso do trator e o proprietário já dispor do necessário e o contrato com trabalhadores locais para preparação das covas e plantio.

Para irrigação do plantio, o produtor utilizará o sistema de gotejamento, pois já o possuía as quantidades de mangueira suficiente, que serviam a outros fins. Nesse sistema, pretende-se usar a menor quantidade de água possível na cova da planta devido o alto controle que o produtor terá. 
Com a realização do projeto, objetiva-se a obtenção por parte do solicitante de uma cultura rentável, que permita uma independência financeira para o próprio, com um produto que tenha qualidade e que supra a expectativa do mercado local.

O pequeno produtor aceitou a implementação da cultura devido conhecimento de informações sobre o lucro obtido através de sua comercialização, baixa mecanização da produção, pequena utilização de agrotóxicos e valor agregado ao produto.

\section{Resultados}

\subsection{Projeção de dados da produção de Maracujá}

As informações de fluxo de caixa que serão apresentados na tabela 1 foram realizados mediante analise de informações coletadas em diversos trabalhos acadêmicos e adaptados para que representassem com máximo de fidelidade a realidade atual de quantidade e valores necessários para a consolidação do projeto no local escolhido.

A estrutura em que se expressa os dados foi feita com a intenção de facilitar a compreensão, concatenando os custos por tipo de operação. O fluxo de caixa foi separado em cálculos anuais, que consideram todas a entradas e saídas de dinheiro nos períodos considerados.

Para que se soubesse a receita anual com a venda do fruto considerou-se um rendimento de 9 $\mathrm{t} /$ ha para o ano 0 de plantio, 17,5 t/ha no primeiro e $13 \mathrm{t} / \mathrm{ha}$ para o segundo, sendo todos esses valores estabelecidos de acordo com uma média que foi calculada a partir dos dados apresentados por Freire Filho et al. (2016). O preço do maracujá foi estimado em $\mathrm{R} \$ 3,00$ por quilogramas.

Tabela 1 - Receita com venda de frutos

\begin{tabular}{ccc}
\hline Período & Rendimento (t/ha) & Receita \\
\hline Ano 0 & 9 & 27000 \\
Ano 1 & 17,5 & 52500 \\
Ano 2 & 13 & 39000 \\
\hline
\end{tabular}

Fonte: Autoria própria

O quadro a seguir mostrará os itens considerados em cada operação que estará presente no fluxo de caixa. 
Quadro 1 - Itens considerados em cada operação

\begin{tabular}{|l|l|}
\hline \multicolumn{1}{|c|}{ Operação } & \multicolumn{1}{c|}{ Itens } \\
\hline Preparo do solo & $\begin{array}{l}\text { Adubo orgânico (Cama de frango); Adubo } \\
\text { mineral (Cloreto de potássio); Covas } \\
\text { (Acabamento/Enchimento); Preparo do solo } \\
\text { (Aração/Gradagem); Preparo do solo } \\
\text { (Marcação/Abertura de covas). }\end{array}$ \\
\hline Prantio & Mudas de Maracujá; Grampos p/ cercas. \\
\hline Tratturais & $\begin{array}{l}\text { Agrotóxico (Clorfenapir 240 G/L, Sulfato } \\
\text { tribásico de cobre 738 G/KG, sulfluramida); } \\
\text { Agrotóxico (Aplicação); Fertirrigação; } \\
\text { Polinização (Manual). }\end{array}$ \\
\hline Colheita & Sacaria p/ maracujá. \\
\hline Espaldeiramento & Construção da Espaldeira. \\
\hline Irrigação & Energia elétrica. \\
\hline
\end{tabular}

Vale salientar que nem todos os itens necessários para a implementação do projeto foram considerados no quadro anterior, pois considerou-se desnecessária a presença dos mesmo na elaboração dos custos, isso pelo fato do proprietário já possuir os mesmo em seu sitio, ou no caso de contratação de serviços o mesmo não necessitaria por possuir conhecimento para realização do mesmo. Dentre esses podemos citar: O Fitilho, arame farpado, estacas, mourões, bomba de irrigação modelo sapo, caixa d'agua de 2500L, mangueiras, e no caso dos serviços de colheita, montagem do sistema de irrigação, podas e replantio não será necessário a terceirização.

A partir de todas as considerações de receitas com venda do fruto e itens de despesa obteve-se os seguintes resultados anuais:

Tabela 2 - Fluxo de caixa para produção no sitio Timbaúba

\begin{tabular}{cccc}
\hline Discriminação & Ano 0 & Ano 1 & Ano 2 \\
\hline A) Entradas & $27.000,00$ & $52.500,00$ & $39.000,00$ \\
Venda do fruto & $27.000,00$ & $52.500,00$ & $39.000,00$ \\
B) Saídas & $19.129,60$ & $13.068,00$ & $12.988,00$ \\
Preparo do solo & $2.706,00$ & 0 & 0 \\
Plantio & $1.116,26$ & 0 & 0 \\
Tratos culturais & 594,28 & 0 & 0
\end{tabular}


Colheita

Espaldeiramento

Irrigação

Depreciação

Salários

Fluxo de Caixa Líquido

(A-B)
160,00

$1.800,00$

225,00

60,00

$12.468,00$

$7.870,40$
315,00

235,00

\section{0}

225,00

225,00

60,00

60,00

$12.468,00$

$12.468,00$

$39.432,00$

$26.012,00$

No item depreciação considerou-se a vida útil de 10 anos para a bomba. O salário representa a remuneração estabelecida para trabalho e utilizou-se como base de cálculo o salário mínimo atual de R \$1.039,00 mensais, não sendo considerados impostos por esse pagamento se efetuar de maneira informal.

\subsection{Payback}

Na tabela abaixo temos o tempo de duração do projeto no sítio Timbaúba, que são de 3 anos, o saldo em caixa e o saldo acumulado para cada ano do projeto.

Observa-se, assim, que no ano zero do projeto já existe retorno do investimento.

Tabela 3 - Períodos do projeto, saldo em caixa e saldo acumulado em reais

\begin{tabular}{ccc}
\hline Período & $\begin{array}{c}\text { Saldo em caixa } \\
(\mathbf{R} \$)\end{array}$ & $\begin{array}{c}\text { Saldo } \\
\text { acumulado }(\mathbf{R} \mathbf{\$})\end{array}$ \\
\hline Ano 0 & $7.870,40$ & $7.870,40$ \\
Ano 1 & $39.432,00$ & $47.302,40$ \\
Ano 2 & $27.012,00$ & $73.314,40$ \\
\hline
\end{tabular}

Fonte: Adaptado de Embrapa (2003)

\subsection{Valor Presente Líquido (VPL)}

Para determinar o VPL foi necessário que se calculasse a Taxa Mínima de Atratividade (TMA) antes. Com isso ponderou-se quanto de dinheiro próprio e quanto de financiamento seria 
necessário para o projeto. Para tal, foi considerado que seria utilizado $50 \%$ via financiamento, que teria um juro de $11 \%$ e que os demais $50 \%$ viria de capital próprio, que se investidos na poupança seria remunerado em 3,35\%. Então o TMA será de:

$$
\begin{gathered}
\mathrm{TMA}=(0,5 \times 0,0335)+(0,5 \times 0,11) \\
\mathrm{TMA}=0,0717 \rightarrow 7,17 \%
\end{gathered}
$$

Usando os dados obtidos para 1ha de Maracujá pode-se calcular o VPL, com TMA de 7,17\% a.a.

$$
\begin{gathered}
V P L=\frac{7.870,40}{(1+0,0717)^{0}}+\frac{39.432,00}{(1+0,0717)^{1}}+\frac{26.012,00}{(1+0,0717)^{2}} \\
V P L=7.870,40+36.793,88+22.647,86 \\
V P L=67.312,15
\end{gathered}
$$

Como o valor do VPL se mostrou positivo, pode-se concluir que o projeto é economicamente viável, pois remunera o que foi investido e consequentemente tem entradas maiores do que saídas no período de duração do projeto, fazendo com que o produtor obtenha lucro.

\subsection{Taxa Interna de Retorno (TIR)}

A fórmula é a mesma para se encontrar o VPL, mas o lado esquerdo da equação igual a zero e variável K a ser encontrada. Na equação abaixo, utilizamos os saldos em caixa de cada ano do projeto e dividindo-os por 1 mais a variável que desejamos encontrar. Elevamos o denominador de cada período ao seu correspondente ano (o valor 7870,40 corresponde ao ano zero, por isso seu denominador está elevado à zero). Caso a TIR for maior ou igual ao TMA, o projeto da produção dos maracujás será aprovado. Assim, temos:

$$
\begin{gathered}
0=\frac{7870,4}{(1+k)^{0}}+\frac{39432}{(1+k)^{1}}+\frac{26012}{(1+k)^{2}} \\
K=252 \%
\end{gathered}
$$

Como os fluxos de caixa são anuais, essa taxa também será anual.

Logo, a TIR é superior a TMA. Sendo assim, o projeto pode ser aprovado para implementação, pois ele paga todo o investimento e consegue ter lucro considerável, com TIR de $252 \%$. Na tabela abaixo se encontram organizados o investimento inicial do projeto, bem como os saldos de caixa e a Taxa de Investimento de Retorno. 
Tabela 4 - Taxa Interna de Retorno

\begin{tabular}{ll}
\hline Investimento & $-4.000,00$ \\
Ano 0 & $7.870,40$ \\
Ano 1 & $39.432,00$ \\
Ano 2 & $26.012,00$ \\
TIR & $252 \%$ \\
\hline
\end{tabular}

Fonte: Adaptado de Embrapa (2003)

\subsection{Relação Benefício/Custo (B/C)}

Como forma de simplificação dos cálculos determinou-se os valores de j que tem a relação direta com o desconto k:

Tabela 5 - Taxas de desconto para $\mathrm{k}-7,17 \%$ a.a.

\begin{tabular}{cccc} 
& Ano 0 (jo) & Ano 1 (j) & Ano 2 (jj) \\
\hline Valores de jn & 1,0000 & 0,9331 & 0,8707 \\
\hline
\end{tabular}

Fonte: Adaptado de Mondaini (2003)

Também se faz necessário a utilização das entradas e saídas para que enfim seja feita a relação Benefício/Custo. A tabela a seguir representa esses valores.

Tabela 6 - Entradas e saídas para o projeto

\begin{tabular}{ccc}
\hline Período & Entradas & Saídas \\
\hline Ano 0 & $27.000,00$ & $19.129,60$ \\
Ano 1 & $52.500,00$ & $13.068,00$ \\
Ano 2 & $39.000,00$ & $12.988,00$ \\
\hline
\end{tabular}

Fonte: Adaptado de Emater/RJ

A partir da manipulação dos dados de entrada e saídas da tabela anterior e as informações de j na tabela 3, é enfim possível a realização do cálculo da Relação B/C para o projeto em analise, apresentando assim o seguinte resultado: 


$$
\begin{gathered}
\frac{B}{C}=\frac{27.000,00 \times 1,0000+52.500,00 \times 0,9331+39.000,00 \times 0,8707}{19.129,00 \times 1,0000+13.068,00 \times 0,9331+12.988,00 \times 0,8707} \\
\frac{B}{C}=2,5790
\end{gathered}
$$

Analisando-se o resultado apresentado, conclui-se que o projeto é economicamente viável pois a Relação B/C é maior que 1 , garantindo um bom retorno ao investimento.

\section{Considerações finais}

Com base nos resultados obtidos pela aplicação dos instrumentos de viabilidade econômica mostra que a exploração do fruto do maracujá na região do Sertão Pernambucano é uma atividade rentável, uma vez que nos inúmeros preceitos de desempenho econômico, os resultados foram consideráveis.

As incertezas que envolvem a atividade agrícola na região e sua viabilidade econômica ao embarcar em um novo plano são notórias para um pequeno agricultor do sertão. Assim, para verificar-se a rentabilidade foram utilizadas quatro ferramentas: TIR, PBS, razão benefício custo e VPL.

A primeira a ser aplicada foi o payback simples onde a projeção de fluxo de caixa feito para um período de três anos, que confirma um rápido retorno do capital investido já no primeiro ano, algo extremamente atraente para o produtor. A segunda foi o VPL onde o valor obtido foi de $\mathrm{R} \$ 67.312,00$, confirmando a viabilidade do projeto. A terceira foi a taxa interna de retorno com o resultado de $252 \%$, esse valor foi superior a taxa mínima de atratividade $7,17 \%$, atendendo o parâmetro para atestar a viabilidade do projeto e para concluir, a ferramenta de custo benefício, tendo um resultado de $\mathrm{R}=2,58$ que serviu para atestar a rentabilidade do empreendimento. Assim todos os resultados obtidos foram positivos para a análise de viabilidade econômica para realização do investimento.

Dessa maneira o estudo proporciona informações relevantes para os pequenos produtores que desejam ingressar na atividade, facilitando assim a tomada de decisão quanto a realizar ou não o investimento. 


\title{
6. Referências
}

\author{
ABRAFRUTAS. LIVRO EM FORMATO DIGITAL SOBRE CULTIVO DO MARACUJÁ É \\ DISPONIBILIZADO GRATUITAMENTE. Disponível em: <https://abrafrutas.org/2019/03/26/brasil-e- \\ atualmente-o-maior-produtor-mundial-de-maracuja/>. Acesso em: 09 fev. 2020.
}

ALMEIDA, Laryssa Souza Bastos de; SANTOS, Anna Carolina Gomes Pires dos; HOLANDA, Laryssa Ramos de. ANÁLISE DE VIABILIDADE ECONÔMICA DE UM PEQUENO PRODUTOR DE MARACUJÁ EM BOCA DA MATA, ALAGOAS. 2018. Disponível em: <http://www.revistasg.uff.br/index.php/sg/article/view/1404/html>. Acesso em: 09 nov. 2019.

ARAUJO, José Lincoln Pinheiro; ARAUJO, Edílson Pinheiro; CORREIA, Rebert Coelho. ANÁLISE DO CUSTO DE PRODUÇÃO E RENTABILIDADE DO CULTIVO DO MARACUJAZEIRO NA REGIÃO DO SUBMÉDIO SÃO FRANCISCO. Disponível em:

<https://www.alice.cnptia.embrapa.br/alice/bitstream/doc/154527/1/OPB205.pdf>. Acesso em: 18 nov. 2019.

DANTAS, K. C. Elaboração e Análise de Projeto para Implantar a Estrutura Necessária a Produção de um hectare de Maracujá Amarelo-azedo na Propriedade do Núcleo Rural de Sobradinho/ DF Brasília: Faculdade UnB de Planaltina (FUP), 2014.

EMBRAPA. Maracujá. Disponível em: https://www.embrapa.br/mandioca-e-fruticultura/cultivos/maracuja. Acesso em: 15 nov. 2019.

FREIRE FILHO, Gilberto de Andrade; LEITE, José Basílio Vieira; RAMOS, José Vanderlei. MARACUJÁ. Disponível em: <http://www.ceplac.gov.br/radar/maracuja.htm>. Acesso em: 09 fev. 2020.

HOJI, Masakazu. Administração Financeira: uma abordagem pratica. 5a ed. São Paulo: ATLAS, 2006. 525.

LIMA, Adelise de Almeida et al. A Cultura do Maracujá. 1994. Disponível em:

<http://ainfo.cnptia.embrapa.br/digital/bitstream/item/162334/1/A-cultura-do-maracuja.pdf〉. Acesso em: 11 nov. 2019.

MATOS, C. M. Viabilidade e análise de risco de projetos de irrigação: estudo de caso do Projeto Jequitaí (MG). Viçosa, MG: UFV, 2002. 142 f. Tese (Mestrado em Economia Aplicada) - Universidade Federal de Viçosa, 2002.

MONDAINI, I.; KINPARA I. D. Avaliação Financeira da Produção de Maracujá. 1. Ed. Planaltina: Embrapa, 2003. 30p.

NOGUEIRA, E. Análise de Investimentos. In: Batalha, M. O. Gestão Agroindustrial. São Paulo: Edit. Atlas, 2001, v. 2.

REZENDE, J.L.P.; OLIVEIRA, A.D. Análise econômica e social de projetos florestais. Viçosa: Universidade Federal Viçosa, 2001

ROZENFELD, H.; FORCELLINI, F.A.; AMARAL, D.C.; TOLEDO. J.C.; SILVA, S.L.; ALLIPRANDINI, D.H.; SCALICE, R.K. Gestão de Desenvolvimento de produtos: Uma referência para a melhoria do processo. 1. ed. São Paulo: Saraiva, 2006.

SEBRAE. MERCADO DE FRUTICULTURA: Panorama do setor no Brasil. Disponível em: http://www.bibliotecas.sebrae.com.br/chronus/ARQUIVOS_CHRONUS/bds/bds.nsf/64ab878c176e5103877bfd 3f92a2a68f/\$File/5791.pdf. Acesso em: 15 nov. 2019.

SOUZA, Alceu e CLEMENTE, Ademir Decisões financeiras e análise de investimentos: fundamentos, técnicas e aplicações. 6. Ed. São Paulo: Atlas, 2008 